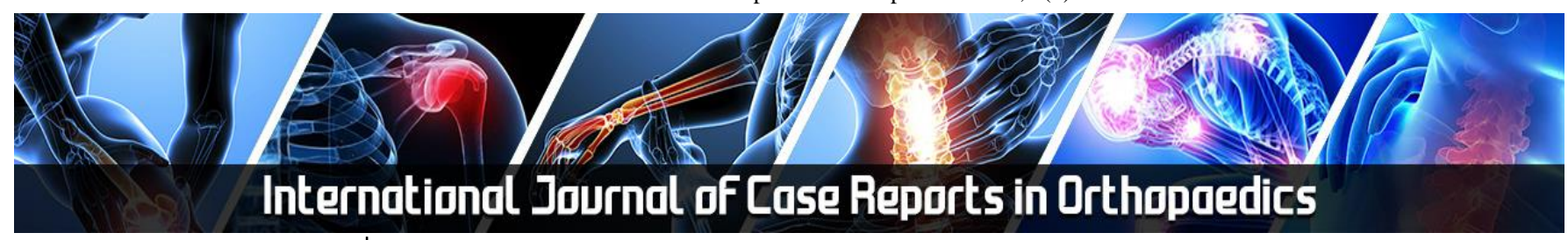

E-ISSN: 2707-8353 P-ISSN: 2707-8345 IJCRO 2021; 3(1): 69-71 Received: 13-12-2020 Accepted: 07-01-2021

Dr. Rajesh K Ambulgekar H.O.D., Department of Orthopedics, Drscgme, Nanded, Maharashtra, India

Dr. Rahul S Agrawal Junior Resident, Department of Orthopedics, Drscgmc, Nanded, Maharashtra, India
Corresponding Author: Dr. Rahul S Agrawal Junior Resident, Department of Orthopedics, Drscgme, Nanded,

Maharashtra, India

\section{A Rare Case Report of Spinal Cord Compression by multiple extra Dural Arachnoid Cyst at Thoracic Level}

\author{
Dr. Rajesh K Ambulgekar and Dr. Rahul S Agrawal
}

DOI: https://doi.org/10.22271/27078345.2021.v3.i1b.50

\begin{abstract}
The patient was a 18 year young male with chief complaint of difficulty in walking \& progressive weakness in left lower limb was diagnosed as having space occupying lesion causing cord compression leading to muscular weakness. There was drastic \& immediate recovery after excision of extradural mass from D3 to D9. A spinal extradural arachnoid cyst is a relatively rare disease.
\end{abstract}

Keywords: Spinal cord tumour, Extra dural spinal arachnoid cyst, Space occupying lesion, Thoracic spine, rare case report

\section{Introduction}

Spinal archanoid cyst are relatively uncommon lesion. Spinal archanoid cyst are of 2 types either intradural or extradural with the intradural variety being rare. Spinal archanoid cyst account for $1 \%$ of spinal cord tumours. It is most commonly seen in young men.

Spinal meningeal cysts have been classified by Nabors et al. into spinal extradural meningeal cyst without nerve root fibres (type I), spinal extradural meningeal cyst with nerve root fibres (type II), and spinal intradural meningeal cyst (type III). The type I cysts are subdivided into type IA (spinal extradural arachnoid cyst) and type IB (occult sacral meningocele) ${ }^{[11]}$. The type II cyst is also known as Tarlov perineural cyst or spinal nerve root diverticulum, while type III cyst is spinal intradural arachnoid cyst. Extradural spinal arachnoid cysts are rare lesions. These lesions are predominantly located in the thoracic region accounting for about $65 \%$ of the cases but have also been found in the lumbar and lumbosacral (13\%), thoracolumbar $(12 \%)$, sacral $(7 \%)$ and cervical regions $(3 \%)^{[1,3-7]}$. They are more commonly located dorsal to the spinal cord, but may also be ventrally located ${ }^{[10]}$. Predominant location of this cyst is in the thoracic region.

Extradural arachnoid cysts may sometimes be asymptomatic ${ }^{[1,7]}$. Whereas, in case of symptomatic cysts, symptoms are due to compression of the spinal cord or nerve roots ${ }^{[1,4]}$ The severity of the symptoms depends upon location and size of the cyst ${ }^{[1,2]}$. The duration of symptoms is shorter in the thoracic spine because of smaller diameter of the spinal canal at this level ${ }^{[10]}$. The diagnostic modality of choice is MRI (Magnetic Resonance Imaging) as it can accurately localize the cyst and can show the size and degree of neural tissue compression ${ }^{[1,2,7]}$. MRI can also help to differentiate arachnoid cyst from other spinal cysts, abscess or cystic tumours. Epidermoid and dermoid cysts often have inhomogenous signal intensity with contrast enhancement of the walls while cystic tumours show contrast enhancing solid parts.

The etiology of spinal archnoid cyst remains unclear.

- In 1962, Perret postulated origin from septum pesticulum of schalbe, an arachnoid rebeculum that divides midline arachnoid space. Although Perret theory explains dorsal cyst it fails to explain ventral cyst.

- A hydrodynamic theory in which CSF pulsation dilate weak areas of arachnoid layer has also been proposed.

- The origination of these cysts could be from arachnoid adhesions secondary to inflammatory process caused by virus, spirochetes, parasites or bacteria.

- Occurrence of arachnoid cyst secondary to trauma (traumatic injury, lumbar puncture, intradural surgery) has also been postulated.

- Archnoiditis (secondary to subarchanoid hemmorhage central media, fibrin glue, meningitis, bone dust). 


\section{Case report}

This 18-year-old boy presented with progressive left lower limb weakness of one month duration with paraesthesia. There was no back pain or sphincteric dysfunction. He had gradual onset weakness leading to patient walking with support. Neurological examination revealed left lower limb weakness, with power grade 4 at left knee \& grade 3 at left ankle of lower extremities. On testing muscle stretch reflexes ankle clonus and knee clonus on left side was observed. Hypoaesthesia below L2 dermatome was found. Straight leg raising (SLR) test was positive.

X-ray dorsal spine AP \& Lateral was done suggestive of normal disc space \& no abnormality was detected. CT whole spine (plain) was done suggestive of multiple extradural cystic lesion extending from D3-D9 level to D9D10 level posteriorly with largest measuring 12x31x69 mm extending laterally through the neural foramina bilaterally with maximum compression of spinal cord at D4, D5, D6 level with minimal spinal cord diameter measuring $5 \mathrm{~mm}$ (Fig A). Thoracic spine MRI showed a cystic lesion compressing the spinal cord posteriorly from T4-T9 (Fig. B).

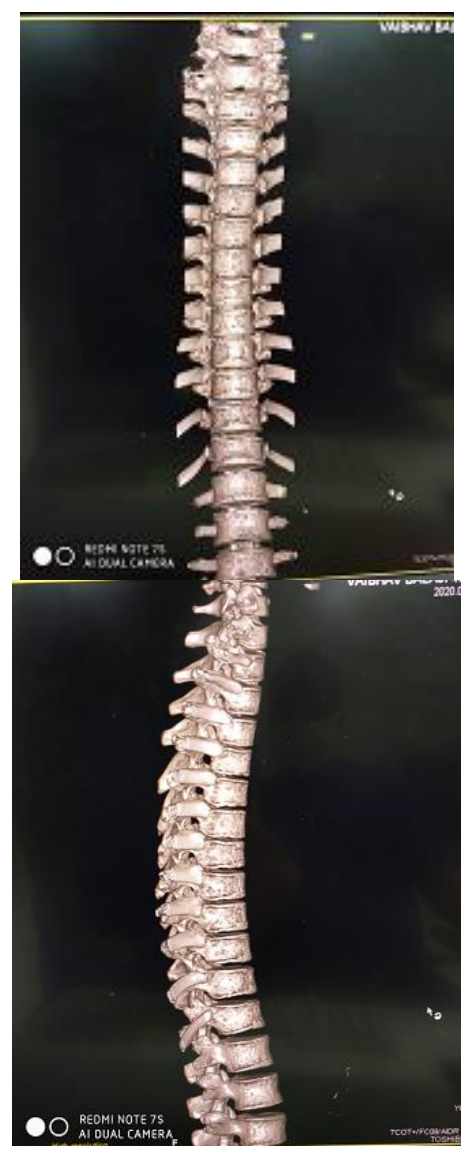

Fig A: (CT High Resolution Images): suggestive of multiple extradural cystic lesion

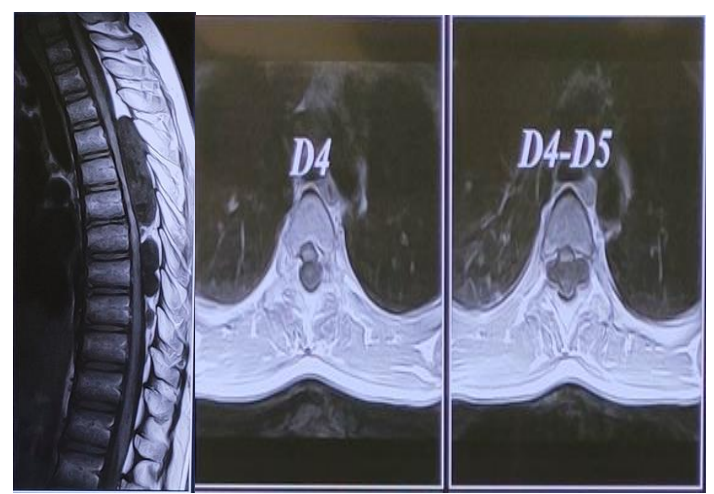

Figure B: T1-weighted MRI showed a cystic lesion with T1low/T2- high intensity at the D3-D9 level

The sample was collected and send for histopathology reporting. It was diagnosed as arachnoid cyst.

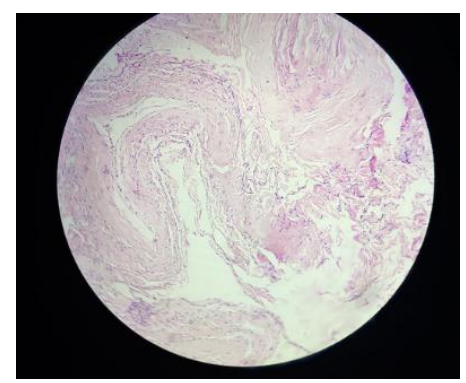

Fig C. On histopathological examination it was diagnosed as arachnoid cyst

We performed a T4-T9 laminectomy and excision of the cyst. The cyst was found to be attached to spinal cord which was separated from spinal cord \& excised with the help of mixtard forcep and dissector. (Fig. C). There was no intra operative complication.

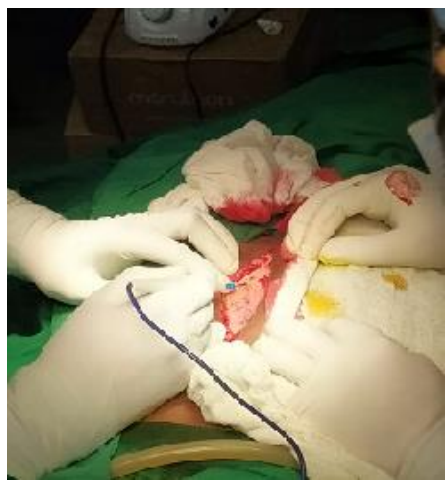

Fig D: Intra-operative image showing arachnoid cyst

There was remarkable post-operative muscle power improvement and patient was ambulating without support after 2 weeks at the time of discharge. The patient did not come for follow up at $1^{\text {st }} \& 3^{\text {rd }}$ month due to his family reasons \& directly came for follow up after 6 months having muscle power grade 5 at hip, knee $\&$ ankle of both lower limb at present.

\section{Conclusion}

Spinal extradural arachnoid cysts are rare causes of spinal cord compression with only few reported cases in the literature. They are mostly located dorsally in the thoracic region and cause symptoms by spinal cord or nerve root 
compression. In this case, the cyst was located dorsally in the thoracic region. There was no history of trauma or spine surgery, therefore cyst is most likely of congenital origin. The operative technique of choice is complete excision of the cyst \& watertight repair of the dural defect to prevent recurrence. A favourable outcome was achieved after surgery and there was drastic \& immediate recovery after excision of extradural mass from D3 to D9 level.
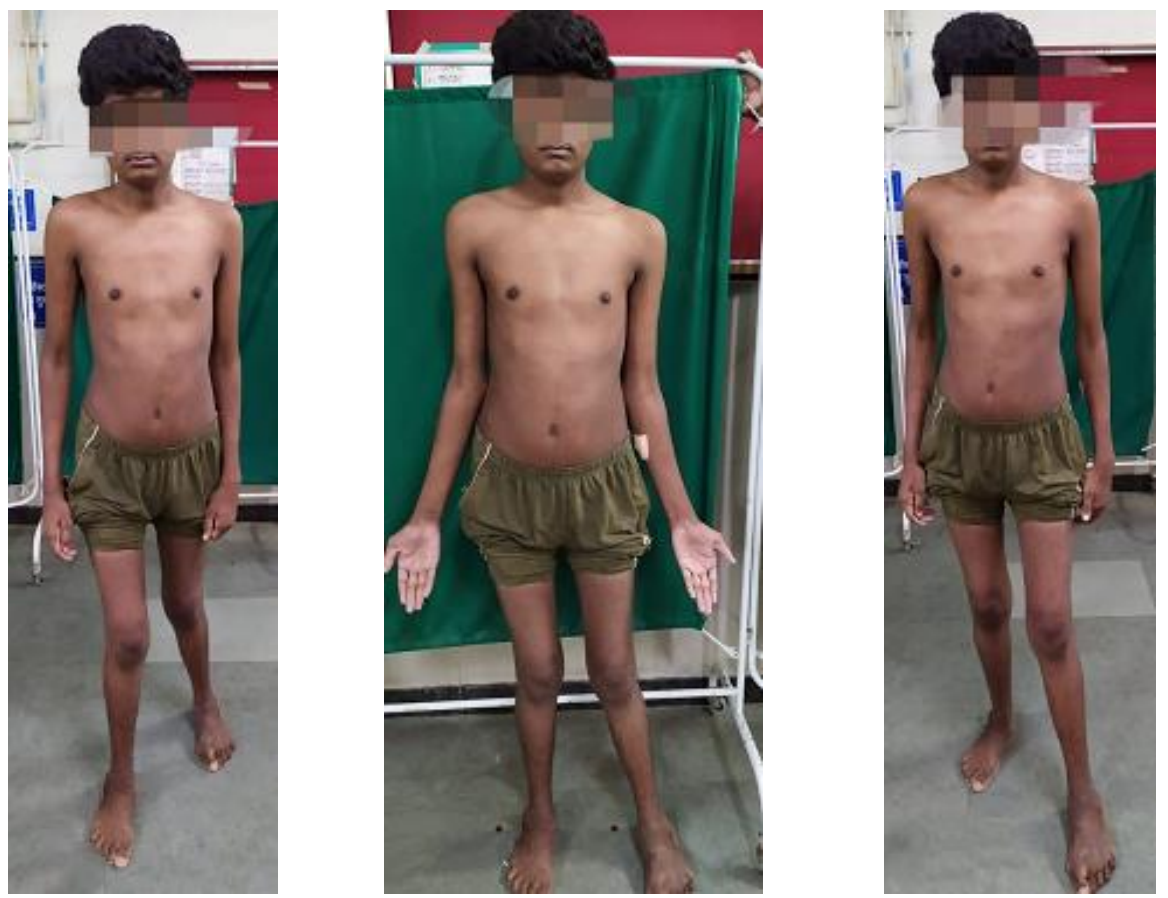

Fig E: Clinical picture of patient post operatively having grade 5 muscle power in both lower limb

Consent: Written informed consent of patient has been taken before publishing the case report.

Conflicts of interest: There are no conflicts of interest.

\section{Financial support \& sponsorship: Nil}

\section{References}

1. Bakhti S, Djaadi L, Terkmani F, Tighilt N, Djennas M. Extradural spinal arachnoid cyst occurring in a child: A case report. Turk Neurosurg 2014;24:90-3.

2. Panigrahi S, Mishra SS, Dhir MK, Parida DK. Giant thoracolumbar extradural arachnoid cyst: An uncommon cause of spine compression. Neurol India 2012;60:540-2.

3. Tomii M, Mizuno J, Takeda M, Matsushima T, Itoh Y, Numazawa $\mathrm{S}$ et al. Thoracolumbar extradural arachnoid cyst-three surgical case reports. Neurol Med Chir (Tokyo) 2013;53:129-33.

4. Kahraman S, Anik I, Gocmen S, Sirin S. Extradural giant multi loculated arachnoid cyst causing spinal cord compression in a child. J Spinal Cord Med 2008;31:306-8.

5. McCrum C, Williams B. Spinal extradural arachnoid pouches. Report of two cases. J Neurosurg 1982;57:849-52.

6. Myles LM, Gupta N, Armstrong D, Rutka JT. Multiple extradural arachnoid cysts as a cause of spinal cord compression in a child. Case report. J Neurosurg 1999;91:116-20.

7. Joaquim AF, Silva EG, Santos MC, Honaroto DC. Giant Cervico-thoracic extradural arachnoid cyst. Arq Neuropiquiatr 2009;67:117-8.
8. Liu SH, Ho JT, Lai PH, Tseng HH, Yip CM, Liao WC, et al. Huge spinal extradural meningeal cyst in the thoracolumbar spine: A case report of a rare cause of low back pain. Kaohsiung J Med Sci 2005;21:427-32.

9. Liu JK, Cole CD, Kan P, Schmidt MH. Spinal extradural arachnoid cysts: Clinical, radiological, and surgical features. Neurosurg. Focus 2007;22:E6.

10. Suryaningtyas W, Arifin M. Multiple spinal extradural arachnoid cysts occurring in a child. J Neurosurg 2007;106:158-61.

11. MW Nabors, TG Pait, EB Byrd et al., "Updated assessment and current classification of spinal meningeal cysts," Journal of Neurosurgery 1988;68(3):366-377. 